\section{Physics for Development: the role of the IGPD at EPS}

\author{
Majed Chergui, Ecole Polytechnique Fédérale de Lausanne, \\ Lausanne-Dorigny, Switzerland
}

$W$ hen looking through the scientific literature, most of us will agree that not much happens in physics in developing countries. Yet, as physicists we all agree that physics can address a large number of problems that developing countries have to face and find cheap and easy solutions to many of them, e.g. production of solar energy, monitoring of urban and rural pollution, medical applications, water purification, etc.

The problems encountered in physics research and training in developing countries are acute. While they may vary from country to country, they obey more or less the same rules: serious lack of funding, which worsens with the economic situation, political instability, wars, isolation of scientists, lack of public awareness, lack of institutional frameworks for research, difficult or no access to scientific publications, etc. The list is too long and we leave it to the collection of articles of this special issue to discuss the situation more in depth and to go into details in some characteristic examples. Yet at the same time, what is being and has been achieved is impressive and deserves admiration, given the local difficulties physicists have to face. In parallel, and despite the many individual initiatives by European scientists to develop links with colleagues from developing coun-

tries, it is fair to say that there is no initiative or policy by European countries, let alone the EU, to strengthen the research potential of developing countries, except for very few exceptions (see article by Furlan). Most of the North-South collaborations in Physics rely more on personal contacts (article by Svanberg and Svanberg and by Kwato Njock), which is fine but far from sufficient.

While the awareness of the EPS for Physics for Development dates back to 1981 when H.Van Regemorter founded the Interdivisional Group of Physics for Development (IGPD) at the European Physical Society (see article by Lillethun and SuzorWeiner), the importance of pursuing the effort and making it more significant is crucial at present. In August 2002, a symposium on Physics and Development was organised during the General EPS conference in Budapest, which brought together physicists from Latin America, Africa and the Arab world (unfortunately the South and South-East Asian participants cancelled their attendance) to discuss the situation with European physicists. The present minispecial edition stems in parts from the discussion that then took place.

Strengthening the research potential in Physics of developing countries is the IGPD main focus, despite its very limited funds.
Three axes are being pursued, in order of priority: a) funding for advanced schools and workshops in Physics in developing countries, with particular emphasis on participation by citizens from developing countries both at the level of lecturers and students; b) funding of the bi-annual Southern European School, which encourages strong participation by students from developing countries (see article by Lillethun and Suzor-Weiner); c) travel grants for short-term training in European laboratories.

In addition, the IGPD aims at becoming a forum for exchange of information and for establishing both South-South and SouthNorth contacts. Along with the efforts of individuals and other organizations both in the industrialized and developing countries (see below for a list of useful organisations), we feel committed to the strengthening of physics research and teaching in developing countries. At a time when physics has become highly international and when European laboratories have more and more doctoral students from developing countries, leaving more than $80 \%$ of the world out of the game is counterproductive and unsafe. The European physics community should grasp the importance and urgency of this issue.

\section{USEFUL LINKS}

\section{Institutions concerned with research in developing countries}

The Abdus Salam International Centre for Theoretical Physics, Trieste (ICTP)

http://www.ictp.trieste.it/

The Abdus Salam International Centre for Theoretical Physics, Trieste Link for publications

http://library.ictp.trieste.it/

African Academy of Sciences (AAS)

http://www.aasciences.org/

Agence Universitaire de la Francophonie (AUF)

http://www.auf.org/

The Alexander von Humboldt Foundation (Germany)

http://www.avh.de/

Arab Science and Technology Foundation (ASTF)

http://www.astf.net

Association of Asian-pacific physical societies (AAPPS)

http://www.aapps.org/

German Academic Exchange Service (DAAD)

http://www.daad.org/

Initiative on Science and Technology for Sustainability (ISTS) http://www.sustainabilityscience.org/ists

International Council of Scientific Unions (ICSU)

http://www.icsu.org

Palestinian European Academic Cooperation in Education

(PEACE PROGRAMME)

http://www.unesco.org/general/eng/programmes/

peace-palestine/

Public Library of Science

http://www.publiclibraryofscience.org/

Third World Academy of Sciences (TWAS)

http://www.twas.org/

World Conference on Science (UNESCO)

http://www.unesco.org/science/wcs 